\title{
Perioperative care in brain arteriovenous malformations
}

\author{
Arthur Maynart Pereira Oliveira', Eberval Gadelha de Figueiredo², \\ Bernardo Assumpção de Monaco ${ }^{1}$, Jorge Dornellys da Silva Lapa ${ }^{3}$, \\ João Welberthon Matos Queiroz ${ }^{4}$, Manoel Jacobsen Teixeira ${ }^{5}$ \\ Divisão de Neurocirurgia do Hospital das Clínicas da Faculdade de Medicina da \\ Universidade de São Paulo (HC-FMUSP), São Paulo, Brasil. \\ Universidade Federal de Campina Grande (UFCG), Cajazeiras, PB, Brasil. \\ Universidade Federal de Sergipe (UFS), Aracaju, SE.
}

\begin{abstract}
The authors provide a review of brain arteriovenous malformations, initially reviewing epidemiological and etiological aspects in addition to the pathophysiology and risk factors associated with bleeding. The emphasis of this review is directed to the clinical and care should be taken since the diagnosis of this pathology, intraoperative management on the viewpoint of the anesthesiologist to the potential complications that occur after resection of the lesion.
\end{abstract}

\section{KEYWORDS}

Arteriovenous malformations/physiopathology, arteriovenous malformations/etiology, preoperative care.

\section{RESUMO}

Cuidados perioperatórios em malformações arteriovenosas encefálicas

Os autores realizam uma revisão sobre malformações arteriovenosas encefálicas, revisando inicialmente aspectos etiológicos e epidemiológicos, além da fisiopatologia e de fatores relacionados com risco de sangramento. A maior ênfase dessa revisão é direcionada para o quadro clínico e para os cuidados que devem ser tomados desde o diagnóstico dessa patologia, o manejo intraoperatório sob o ponto de vista do anestesista, até as possíveis complicações que ocorrem após a ressecção da lesão.

\section{PALAVRAS-CHAVE}

Malformações arteriovenosas/fisiopatologia, malformações arteriovenosas/etiologia, cuidados préoperatórios.

\section{Introduction}

Arteriovenous malformation (AVM) can be characterized as a vascular network with high flow connections between the arterial and venous segment, with the absence of a capillary bed brought in its centro (Figures 1 , 2 and 3). ${ }^{1}$ Usually consists of one or more feeder arteries that supply a poorly developed vascular group (Nidus) that drains to one or more veins with early filling and end up with evolving arterial characteristics. The exact moment of the development of an AVM remains uncertain, with great chances of emergence during embryonic vascular development.
Even with the possibility of prenatal diagnosis of other pathologies such as cerebral aneurysms of Galen's ampulla, the AVM are usually not diagnosed in this period. ${ }^{2}$ Mutations in germ cells, that act in pathways of angiogenesis, the endothelial receptor Tie Angiopoietin-2, TGF-beta, nitric oxide synthase, VEGF and FGF-2 are potential promoters of erratic angiogenesis and possibly associated with the genesis of AVM and other cerebral vascular malformations. ${ }^{3-5}$

Usually has a triangular shape with its base facing the meninges and the apex toward the ventricular system. ${ }^{6}$ Their location in the transition zones between anterior, middle and posterior arterial segments may

1 Médico-residente da Divisão de Neurocirurgia do Hospital das Clínicas da Faculdade de Medicina da Universidade de São Paulo (HC-FMUSP), São Paulo, SP, Brasil.

2 Supervisor da Divisão de Neurocirurgia do HC-FMUSP, São Paulo, SP, Brasil.

3 Graduando em Medicina da Universidade Federal de Sergipe (UFS), Aracaju, SE, Brasil.

4 Graduando em Medicina da Universidade Federal de Campina Grande (UFCG), Cajazeiras, PB, Brasil.

5 Professor titular de Neurocirurgia do HC-FMUSP, São Paulo, SP, Brasil. 


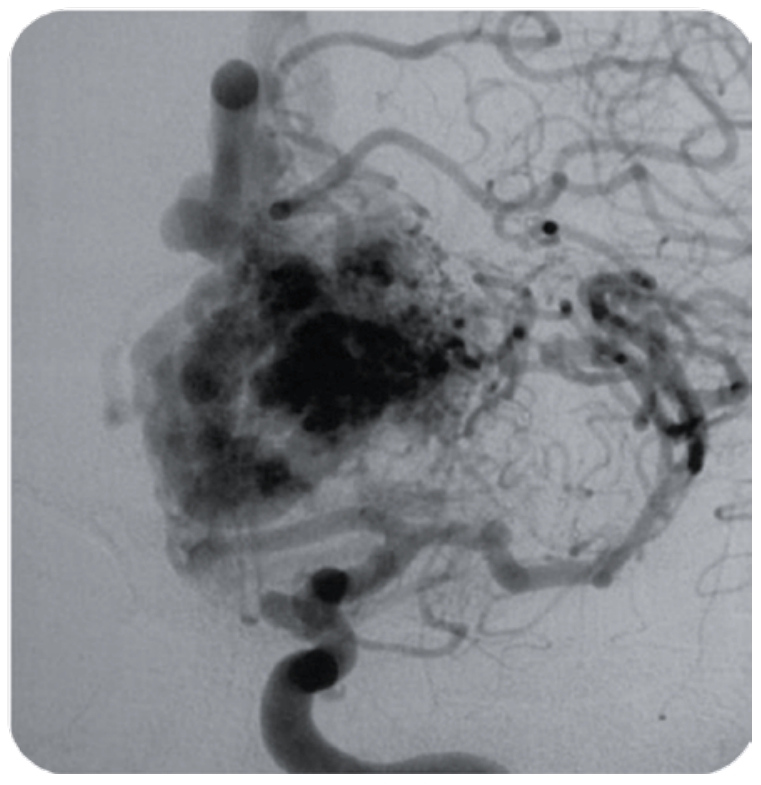

Figure 1 - Frontal AVM draining into the superior sagittal sinus. Preoperative angiography.

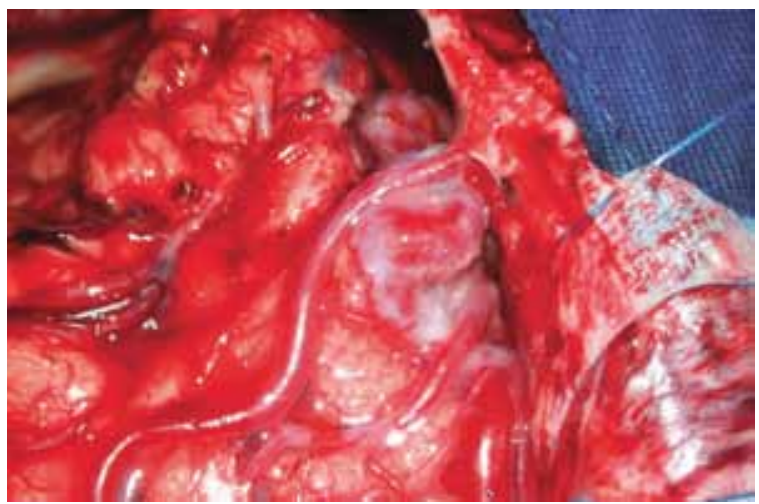

Figure 2-AVM surgical overview and interhemispheric fissure.

suggest its appearance during the late birth when these vascular transition regions are formed. ${ }^{7}$ Anatomically there is a sudden transition between arteries with variable amount of smooth muscle and elastic lamina with thin-walled veins infiltrated by fibroblasts. You can also find signs of previous thrombosis and recanalization, products of hemoglobin degradation and calcifications related to previous hemorrhage.

The most affected age group is between 20 and 40 years with slight male predominance and although they are more frequent in supra-tentorial compartment can also be found in the cerebellum, brainstem and spinal cord. Your bleeding represents approximately $2 \%$ of all Stroke and $38 \%$ of spontaneous hemorrhage in patients

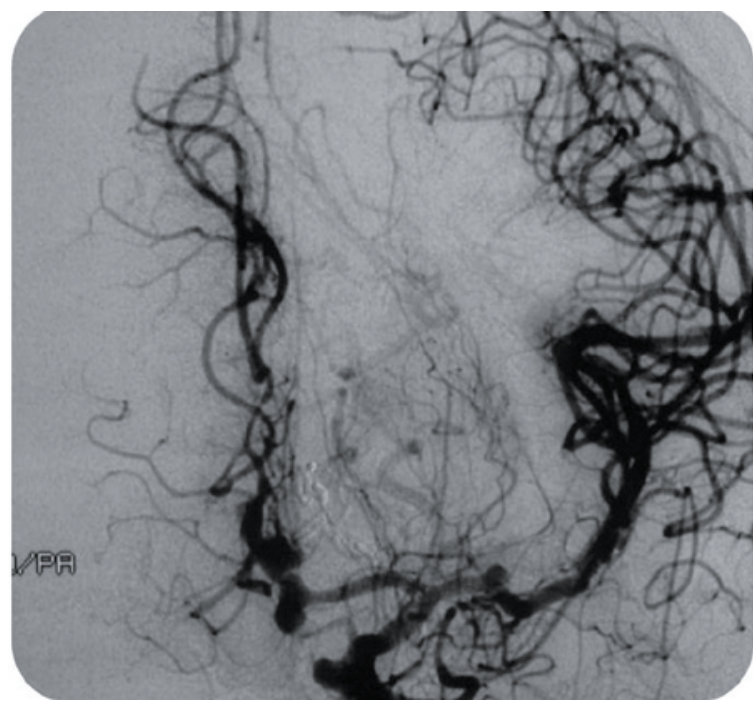

Figure 3 - Postoperative angiography showing complete resection of the lesion.

between 15 and 45 years. The incidence of AVM is highly variable when evaluating data from autopsy in large hospitals series, ranging from 5 to 613 cases per 100,000 individuals. ${ }^{8-10}$ However this value eventually falls when prospective data are used, with 0.55 to 1.21 cases per 100.00 individuals. ${ }^{11-13}$

\section{Physiopathology of arteriovenous malformations}

Development and origin of an AVM still without definitive explanation. Genetic changes may be related to the genesis of these vascular pathology in its sporadic or familiar presentation ${ }^{13,14}$ and may also be related to systemic diseases as well known as the Osler-WeberRendu syndrome, Sturge-Weber and Wyburn-Mason syndromes. Another aspect that contributes to a genetic relationship is the increase in incidence of AVM in hereditary hemorrhagic teleangiectasy, with $1 \%$ and $10 \%$ of incidence in their subtype 2 and 1 respectively. According to the latest theories AVM are related to intense endothelial proliferation with vascular remodeling mediated by inflammatory factors, which associated with growing lesions after diagnosis and regrowth after appropriate treatment support the theory of a dynamic disease and not only the persistence of a neonatal aberrant angiogenesis. ${ }^{15}$

The understanding of hemodynamic factors related to AVM is essential to understand its evolution and 
morphological changes. The contrast speed through the AVM represents a parameter to measure their pressure and resistance, with lesions that have a high flow and low resistance in the feeder arteries mainly found in patients with symptomatic seizures. When there is increased resistance and pressure in these arteries, as evidenced by a slowing of the contrast velocity through the nidus, there is an increased propensity for hemorrhage. AVM of small size have a greater resistance to flow, more pressure on the feeder arteries and a greater chance to evolve with bleeding while larger lesions would have less chance of bleeding from the low pressure in the feeder arteries. ${ }^{6,16-18}$

\section{Clinical presentation}

The exact number of asymptomatic patients with AVM is not well understood, with population studies showing incidence of $2 \%$ to $40 \%{ }^{11}$ The bleeding seems to be the most frequent symptom in AVM, often approximately $65 \%$ of cases diagnosed as early symptom, with a frequency in patients under 40 years of approximately $72 \%$. Parenchymal hemorrhages is the most frequent pattern followed by intraventricular hemorrhage and subarachnoid successively. ${ }^{11,19,20}$ The subarachnoid hemorrhage usually is not related to vasospasm, and only $0.6 \%$ of spontaneous subarachnoid hemorrhage are attributed to AVM. The overall risk of bleeding from an AVM is around $2 \%-4 \%$ per year with possible factors influencing the occurrence of bleeding.

AVM located in the basal ganglia, the periventricular region and posterior fossa have a higher propensity to bleed. Although controversial, some studies have shown that AVM smaller than $3 \mathrm{~cm}$ bleed more, ${ }^{19,21}$ while other author evaluated 27 patients with larger than $5 \mathrm{~cm}$ AVM and observed initial bleeding symptom in 12 patients. ${ }^{22}$ Other indirect mechanical factor that cause increased venous or feeder arteries pressure can also increase the risk of hemorrhage.

Approximately $15 \%-35 \%$ of patients with AVM present initially with seizures, isolated or associated with hemorrhage. Crises can be triggered by mass effect with cortical irritation, theft flow or ischemic regions from previous hemorrhagic events. The presence of cortical AVM, high flow through the feeder artery, changes in venous drainage increase the chance of developing seizures.

Headache is a common complaint in $15 \%$ of patients with AVM and be related to recruitment of meningeal blood supply, with a greater chance of being observed in occipital AVM. Ten percent of patients with AVM may also present permanent or temporary deficit, not associated with bleeding or seizures, but caused by theft flow exercised by arterial fistula. Areas requiring a greater blood supply may suffer a greater loss, which may precede other more intense symptoms, manifesting itself in subtle ways by learning difficulties.

\section{Anesthetic procedure in AVM surgery}

Advances have been achieved in neuroanesthesia the past 10 years. Among these advances in the management of neurosurgical patients is the most appropriate use of barbiturates, hypothermia and intraoperative neurophysiological monitoring with electro encephalogram (EEG) and continuous assessment of the somatosensory evoked potential. Even with advances, the basic goal of anesthesia is the same to provide an adequate surgical environment without compromising patient safety.

Patients who undergo surgery initially receive a pre-anesthetic mild sedation with 2-5 mg midazolam before entering the operating room, allowing reduction of surgical stress. During intubation should be avoided acute elevations of blood pressure (BP) because of premature hemorrhage. At this moment are applied doses of opioids (fentanyl) and hypnotics (midazolam) in addition to neuromuscular blocking agents when necessary. If there is a high probability of blood pressure increase can also be used beta blockers (labetalol or esmolol).

In this surgery is required a rigorous and extensive monitoring of cardiac, respiratory and neurophysiological parameters. All patients should be monitored with cardioscope, oximetry, and measurement of expired $\mathrm{CO}_{2}$ concentration $\left(\mathrm{ETCO}_{2}\right)$. In addition, they receive a central venous access, which serves to infuse anesthetic drugs, volume, vasoactive drugs and blood products. Continuous assessment of BP invasively by radial artery catheterization, it is also mandatory.

Large volume hemorrhages from AVM may evolve with worse neurologic and clinical status. In such cases there is great risk of developing secondary cardiovascular diseases (acute myocardial infarction and arrhythmias) plus the possibility to evolve with consumption coagulopathy and increased risk of bleeding during surgery. At this time the neurosurgeon may also require more active maneuvers to reduce intracranial pressure (ICP). After a quick evaluation of global hemodynamic condition of the patient the anesthetist can use furosemide or mannitol in order to reduce the intravascular volume with consequent reduction in cerebral blood volume and ICP. When there is possibility of scheduling the surgery and there are large mass effect or edema associated with the 
MAV, you can use an external lumbar shunt in order to reduce the volume of cerebro spinal fluid. During surgery the drain is open allowing less manipulation of vital structures to the patient.

In general the main focus of the anesthetic procedure is the absolute control of the $\mathrm{BP}$ reducing as much as raising their levels. The BP is often maintained at baseline levels for the patient being operated on or slightly lower than normal. Furthermore, attempts to maintain the $\mathrm{ETCO}_{2}$ between 25 to $30 \mathrm{mmHg}$ associated with low fluid administration, trying to reduce the cerebral blood volume. If require temporary clipping of large vessel hypothermia can be used with or without hypertensive drugs and deepening the sedation level with barbiturates and recorded by EEG. After resection of the AVM neurosurgeon may request that the anesthetist artificially raise the BP to investigate possible residual foci of the nidus, or made an angiogram with the same goal.

At the end of the surgery the patient is left under anesthesia while skull fixing is removed. At this stage there should be more careful to prevent any sudden increases in BP. All patients should be referred to an Intensive Care Unit and the option for early extubation or not depends on any complications that occurred during the procedure. In cases of small AVMs with surgery without complications the patient may still be extubated in the operating room while large AVM with difficult approach or when associated with large parenchymal manipulation should be kept sedated for 12 to 24 hours and if necessary with maneuvers of neuroprotection (hypothermia, barbiturates).

\section{Postoperative complications}

\section{Hemorrhage}

Even with the final surgeon impression of complete AVM removal, some small residual fragments may go unnoticed. Pressure variations in the postoperative period associated with not scar tissue in the surgical bed can trigger large hemorrhages. To avoid this complication we can perform an intraoperative angiography for better control of the resection. Some surgeons prefer to do all the surgery with normal BP status, thus avoiding the non-visualization of residual AVM that occurs when it instituted a system of hypotension during the procedure. Another countermeasure is to perform a small BP elevation of $20-30 \mathrm{mmHg}$ above the basal pressure during surgery to ensure that no residual AVM.

\section{Arterial-venous-capillary hypertension syndrome}

After resection of AVM, especially those larger than $4 \mathrm{~cm}$, local hemodynamic change may occur associated with hemorrhage and cerebral edema, which were previously called the "normal perfusion pressure breakthrough", hyperemia related to venous occlusion, congestive apoplexy, or "overload". In 1978, Spetzler et al..$^{23}$ described the phenomenon of breakthrough, as the loss of the local auto regulation characterized by the inability of the capillary bed to protect the reactive increased perfusion due to the AVM resection, resulting in a local hyperemia.

Despite this evidence many patients with reactive hyperemia in the postoperative period did not develop hemorrhage or edema. As the size of the feeder arteries of AVM does not return immediately to its normal diameter after nidus resection, they continue to have lower resistance to flow than the normal arteries. With its increased diameter they end up showing an increase in pulsatility and increased peak pressure in the cardiac systole, then having some impairment of arterial integrity with possible rupture and bleed. The most prone to break are those who already have compromised vessel structure just prior to resection of AVM, especially aneurysmatic dilatations that were not excised or regions of the artery wall weakened by chronic hypertension.

\section{Vasospasm and seizures}

Unlike subarachnoid hemorrhage occurrence of vasospasm after resection of an AVM is infrequent (2\%), except in cases where dissection is associated with large vessels, whereupon incidence increases to $27 \% .^{24}$

Any neurosurgical procedure with cortical manipulation may end up triggering seizures. The incidence of seizures in patients who already had seizures preoperatively reaches around $40 \%$, whereas for patients who had no seizures before surgery the incidence may be $10 \% .25,26$ Among the factors more related to the development or persistence of crises in the postoperative period are the occurrence of multiple seizures preoperatively, the presence of a neurological deficit for 12 months, beginning with bleeding symptoms and the presence of a nidus greater than $3 \mathrm{~cm} .{ }^{27}$

\section{References}

1. Stapf C, Mohr JP, Pile-Spellman J, Solomon RA, Sacco $\mathrm{RL}$, Connolly ES Jr. Epidemiology and natural history 
of arteriovenous malformations. Neurosurg Focus. 200;11(5):e1.

2. Campi A, Scotti G, Filippi M, Gerevini S, Strigimi F, Lasjaunias P. Antenatal diagnosis of vein of Galen aneurysmal malformation: MR study of fetal brain and postnatal follow-up. Neuroradiology. 1996;38(1):87-90.

3. Hashimoto T, Lam T, Boudreau NJ, Bollen AW, Lawton MT, Young WL. Abnormal balance in the angiopoietin-tie2 system in human brain arteriovenous malformations. Circ Res. 2001;89(2):111-3.

4. Hatva $\mathrm{E}$, Jääskeläinen J, Hirvonen $\mathrm{H}$, Alitalo $\mathrm{K}$, Haltia M. Tie endothelial cell-specific receptor tyrosine kinase is upregulated in the vasculature of arteriovenous malformations. J Neuropathol Exp Neurol. 1996;55(11):1124-33.

5. Hirschi KK, Rohovsky SA, D'Amore PA. PDGF, TGFbeta, and heterotypic cell-cell interactions mediate endothelial cell-induced recruitment of $10 \mathrm{~T} 1 / 2$ cells and their differentiation to a smooth muscle fate. J Cell Biol. 1998;141(3):805-14.

6. Bor-Seng-Shu E, Kita WS, Figueiredo EG, Paiva WS, Fonoff ET, Teixeira MJ, et al. Cerebral hemodynamics: concepts of clinical importance. Arq Neuropsiquiatr. 2012;70(5):352-6.

7. Ondra SL, Troupp H, George ED, Schwab K. The natural history of symptomatic arteriovenous malformations of the brain: a 24-year follow-up assessment. J Neurosurg. 1990;73(3):387-91.

8. Courville CB. Intracranial tumors. Notes upon a series of three thousand verified cases with some current observations pertaining to their mortality. Bull Los Angeles Neurol Soc. 1967;32(3 Suppl 2):1-80.

9. Jellinger $\mathrm{K}$. Vascular malformations of the central nervous system: a morphological overview. Neurosurg Rev. 1986;9(3):177-216.

10. Mccormick WF. Pathology of vascular malformations of the brain. In: Wilson CB, Stein BM, editors. Intracranial arteriovenous malformations. Baltimore: Williams \& Wilkins; 1984. p. 44-63.

11. Brown RD Jr, Wiebers DO, Torner JC, O'Fallon WM. Incidence and prevalence of intracranial vascular malformations in Olmsted County, Minnesota, 1965 to 1992. Neurology. 1996;46(4):949-52.

12. Jessurun GA, Kamphuis DJ, Van der Zande FH, Nossent JC. Cerebral arteriovenous malformations in The Netherlands Antilles. High prevalence of hereditary hemorrhagic telangiectasia-related single and multiple cerebral arteriovenous malformations. Clin Neurol Neurosurg. 1993;95(3):193-8.

13. Achrol AS, Kim H, Pawlikowska L, Trudy Poon KY, McCulloch CE, Ko NU, et al. Association of tumor necrosis factor-alpha-238G $>$ A and apolipoprotein E2 polymorphisms with intracranial hemorrhage after brain arteriovenous malformation treatment. Neurosurgery. 2007;61(4):731-9.

14. van Beijnum J, Van der Worp HB, Schippers HM, Van Nieuwenhuizen O, Kappelle LJ, Rinkel GJ, et al. Familial occurrence of brain arteriovenous malformations: a systematic review. J Neurol Neurosurg Psychiatry. 2007;78(11):1213-7.

15. Achrol AS, Guzman R, Varga M, Adler JR, Steinberg GK, Chang SD. Pathogenesis and radiobiology of brain arteriovenous malformations: implications for risk stratification in natural history and posttreatment course. Neurosurg Focus. 2009;26(5):E9.

16. Henkes H, Gotwald TF, Brew S, Kaemmerer F, Miloslavski E, Kuehne D. Pressure measurements in arterial feeders of brain arteriovenous malformations before and after endovascular embolization. Neuroradiology. 2004;46(8):673-7.

17. Norris JS, Valiante TA, Wallace MC, Willinsky RA, Montanera WJ, terBrugge $\mathrm{KG}$, et al. A simple relationship between radiological arteriovenous malformation hemodynamics and clinical presentation: a prospective, blinded analysis of 31 cases. J Neurosurg. 1999;90(4):673-9.

18. Spetzler RF, Hargraves RW, McCormick PW, Zabramski JM, Flom RA, Zimmerman RS. Relationship of perfusion pressure and size to risk of hemorrhage from arteriovenous malformations. J Neurosurg. 1992;76(6):918-23.

19. Sarwar M, McCormick WF. Intracerebral venous angioma. Case report and review. Arch Neurol. 1978;35(5):323-5.

20. Jomin M, Lesoin F, Lozes G. Prognosis for arteriovenous malformations of the brain in adults based on 150 cases. Surg Neurol. 1985;23(4):362-6.

21. Langer DJ, Lasner TM, Hurst RW, Flamm ES, Zager EL, King JT Jr. Hypertension, small size, and deep venous drainage are associated with risk of hemorrhagic presentation of cerebral arteriovenous malformations. Neurosurgery. 1998;42(3):481-6.

22. Sadasivan B, Hwang PY. Large cerebral arteriovenous malformations: experience with 27 cases. Surg Neurol. 1996;45(3):245-9.

23. Spetzler RF, Wilson CB, Weinstein P, Mehdorn M, Townsend $\mathrm{J}$, Telles D. Normal perfusion pressure breakthrough theory. Clin Neurosurg. 1978;25:651-72.

24. Morgan MK, Sekhon LH, Finfer S, Grinnell V. Delayed neurological deterioration following resection of arteriovenous malformations of the brain. $\mathrm{J}$ Neurosurg. 1999;90(4):695-701.

25. Piepgras DG, Sundt TM Jr, Ragoowansi AT, Stevens L. Seizure outcome in patients with surgically treated cerebral arteriovenous malformations. J Neurosurg. 1993;78(1):5-11.

26. Yeh HS, Tew JM Jr, Gartner M. Seizure control after surgery on cerebral arteriovenous malformations. J Neurosurg. 1993;78(1):12-8.

27. Crawford PM, West CR, Shaw MD, Chadwick DW. Cerebral arteriovenous malformations and epilepsy: factors in the development of epilepsy. Epilepsia. 1986;27(3):270-5.

Correspondence address

Arthur Maynart Pereira Oliveira

Rua Construtor Cunha, 69, ap. 1.203

49027-340 - Aracaju, Sergipe, Brasil

E-mail: arthurncr2007@gmail.com

Tel.: (+55 79) 9994-0525/Telefax: (+55 11) 3069-8014 